\title{
Rapid Diagnosis and Evaluation of Agricultural Drought Based on Machine Learning Language
}

\author{
Pavan Mohan. N \\ Department of Electronics and Communication Engineering, SRM University - AP, Andhra Pradesh, India \\ npavanmohan3@gmail.com
}

\begin{abstract}
Global climate change causes a decrease in precipitation in India, as in many other places around the globe. As a result, droughts have occurred over a large area and in a more drastic way than in the past. The present study focuses upon assessment of meteorological drought conditions with Machine learning algorithms, such as Support Vector Machine (SVM) and Decision Tree (DT) based upon the measurement of precipitation over 36 meteorological -subdivisions in India. Meteorological drought occurs when precipitation is less than average over a prolonged time scale. It usually precedes various kinds of drought and adversely affects the environmental, economic and social conditions. Among various methods for assessment of meteorological drought by using drought indices, Machine learning algorithms can be of vital use in evaluating systems. Operating on multi-sensory data sets like SVM and DT, we will have far-reaching impacts to overcome socio- economic vulnerability in India. However, this preliminary study is focused on precipitation impacting meteorological drought. Building on the Machine learning algorithms, it is now possible to timely conduct realtime evaluation by SVM and DT applications. This approach will help us to have a refined view of drought transformations, Timely comprehensive analysis, severity and trends of meteorological drought category. Other drought interactions that are still relatively unknown, particularly in India, are to be more focused.
\end{abstract}

Keywords: Decision Tree, Meteorological Drought, Support Vector Machine

\section{Introduction}

Research studies and investigations have characterized drought as an imbalance in water regimes. This occurs due to lower than the average precipitation, accompanied by a reduction in water resource availability [1]. Inconsistent rainfall patterns are a major reason for drought.

Meteorological drought assessment is our primary objective and is viewed in perspective as a relation between amounts of normal rainfall with dry spell duration. This is indicated as a lower- than-average rainfall over a period time and or early departure in the rainfall patterns. It adversely affects water resource availability and has a serious impact on agricultural productivity. Meteorological drought is prelude to other drought forms and negatively impacts the economy.

Consequence on agriculture is subjected to the duration and meteorological drought severity. This hampers crop productivity and the impact varies on different cropping patterns, across soils and geographical regions. The phenomenon of precipitation decline is the initiation of drought formation. Decline in rainfall over time and upon a wide area, causes meteorological drought. This can be assumed to be the initial stage of the formation of drought. The persistence of its occurrence in hydrological cycles leads to differing degrees of drought. Apart from this, as an outcome of increased evaporation, soil moisture diminishes and precipitation decreases [2].

Drought often develops steadily and accumulates slowly having a long-lasting influence. Repeated and prolonged droughts have also led to various undesirable consequences [3]. Drought has been described by the "Indian Meteorological Department" (IMD) as a condition that occurs in any region when the average annual rainfall is below $75 \%$ of normal rainfall [4].
Further, IMD has categorized droughts into broad categories namely, a severe drought if the rainfall deficiency exceeds $50 \%$ of the normal rainfall. Moderate drought with a rainfall ranging between $25 \%$ to $50 \%$ of normal rainfall [5], [6]. In case of meteorological droughts, effectiveness of precipitation should overrule amount of precipitation.

Average of the annual rainfall in India is 118 centimeters, which is scaled to be excessive for country of its comparable size around the globe. The unreliable SouthWest monsoon which sometimes is unpredictable, intermittent and irregular rainfall patterns causes floods and absence of seasonal rainfall causes drought.

In India, principal cause of meteorological droughts can be summarized as under

- Lack of depressions causes lean monsoon and belowaverage rainfall.

- Late-onset or early retreat of monsoons

- Break down in monsoons over a prolonged period

- Retribution of the jet stream's southern branch

In India, rainfall is due to South-West (June- September) and North-East monsoons (October- December). Around three-fourths of yearly rainfall is received in India due to South-West monsoon and irregular patterns of South-West monsoon, with lengthy - dry spells and high temperatures, are mainly accountable for drought [7]. States of Andhra Pradesh, Bihar, Gujarat, Jharkhand, Karnataka, Maharashtra, Rajasthan, Tamil Nadu, Telangana and regions of the northeast are drought- prone. The said states are home to 500 million population, nearly $40 \%$ of the country's population. 


\section{Background}

Support Vector Machine (SVM) a supervised method utilized for the regression and the classification for a broad data. Previous applications of SVM have shown its versatility in understanding hydrological and climatic studies [8]- [11]. Graphics depicting discrepancies between expected and observed circumstances (values) is an important tool used for tracking model performance [12]. SVM is the new era of mathematical learning techniques aimed at the recognition of data structures [13].

The formulation of SVM is based on the Structural Risk Minimization (SRM). The implementation of SVM has been shown to contribute for improved results than traditional Empirical Risk Minimization (ERM). Changes appear over the process in attributes and as a consequence, the data produced in all systems require continuous monitoring and the identification of existing models, if any.

A further feature of SVM when detecting the data structure is the conversion of original data from input space or feature space by a mathematical paradigm called kernel function which includes theorem linear function [14].

SVM was applied in remotely sensed image classification and rainfall modelling. The comparison between Artificial Neural Network (ANN) and SVM was utilized for conceptual rainfall/ runoff modelling in three catchments and it was demonstrated that SVM performed comparatively better [15]. Extensive research on drought, from different perspectives was done. Drought was observed by meteorologists as an outcome of rainfall, temperature, humidity and evaporation. Engineers have visualized drought impact in the point of view of water sources like rivers, reservoirs, ground water and lakes. The agrarian community considers drought forms with reference to crop productivity and by economists in regard to human life.

Data mining helps in arriving at formulae and rules that allow substantial data to predict the upcoming using computational techniques. Data based models like Decision Tree (DT) and advancements over the years have paved way for progress of new approaches of drought prediction.
Previous findings have shown that drought impacts on agriculture were because of complex atmospheric and biophysical processes. Data mining offered pathways to observe the drought character over a time period. Data mining components like clustering, regression, DT algorithms and their utilization for hydro- meteorological data were presented [12]. Comparison of physics-based and data-based models was clarified and general definitions were given regarding methods of data mining and their implementations in control of water resources [16]. In rainfall flow modelling, M5 tree and ANN methods were compared. It was inferred that M5 Tree model for the data analysis gave significant outcomes than ANN [17].

Empirical data modelling and its performance was studied using a designed metamodel. This model was recognized to be strongly affected by the non-uniformity, complexity and scarce distributions of input space challenges. Many of them were of high dimensionality. As an effect, the question could appear in ill-possessed circumstances [18].

Determination of reservoir management rules in England [19] and in India [20] was done using linear programming employing data mining, by an "if conditional" approach. They inferred that data mined rules come closest to optimization results. These results were generated using the C 4.5 Decision Tree technique [21]. Data mining helped to define complex interactions with ocean- atmosphere factors which are resultants of droughts over regions of Nebraska, USA. It was observed that data mining algorithms increase efficiency in decision making and to make optimal choices of planning and preparedness [22]. It was found that data mining tools can also be used in predicting future trends and behaviour, allowing businesses to make proactive, knowledge driven decisions [23], [24].

Drought analysis in the region of Ankara has shown a decrease in percentage of errors as the number of rules increased. It was also summarized that the number of rules derived from the decision tree ranged from 4 to 8 , with the lowest amount of error ranging from $0-4.5 \%$ for the training period and $0-16 \%$ for the test period [25].

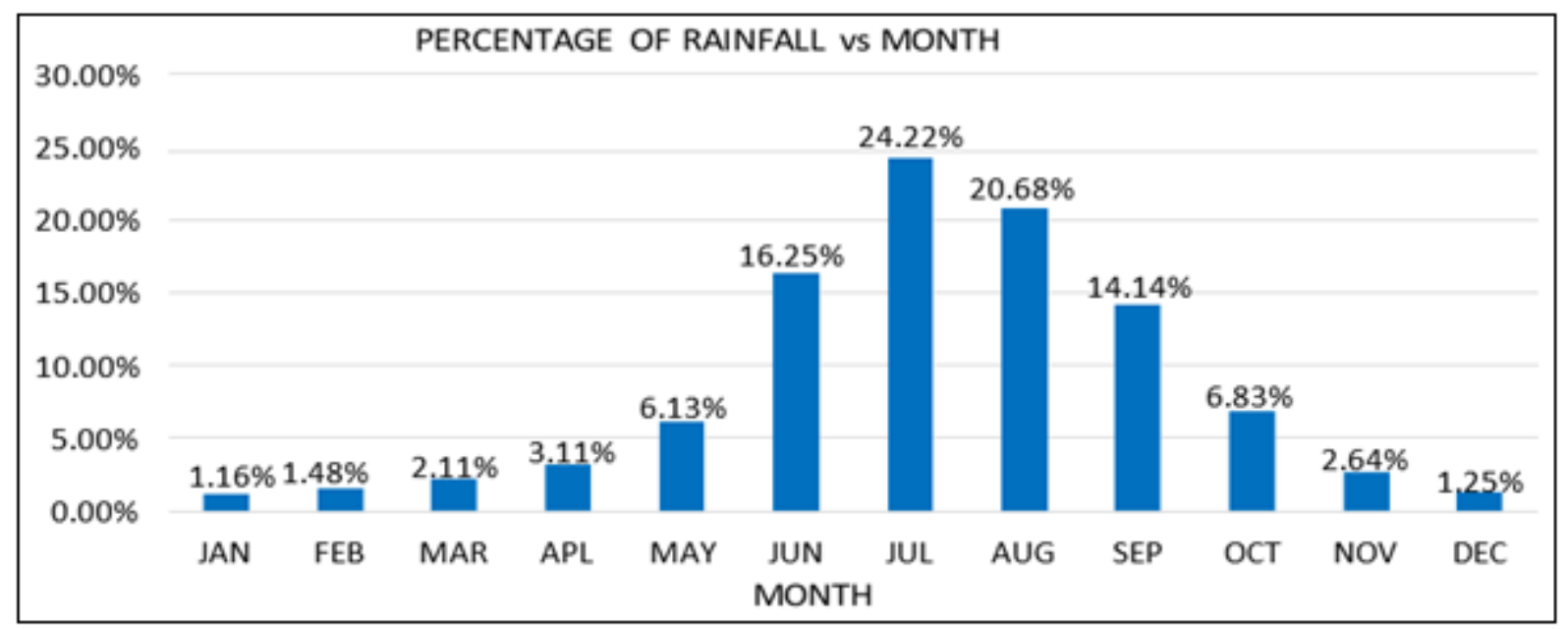

Figure 1: Illustration of monthly rainfall percentage 
Studies on sediment transport analysis were done to estimate river bed load using ANN and also decision tree method. They compared the outcomes with the widely used models and summarized that in complex sediment transportation studies, data mining was a true and effective method [26].

Predictive power of ML models was assessed for mapping shallow landslide susceptibility using the validation data set. The accuracy scores for SVM and Alternating DT were found to be $88.5 \%$ and $76.0 \%$, respectively. Finally, results from the training and validation sets showed that SVM outclassed Alternating DT model in predicting the locations of landslides in the study area [27].

\section{Methodology}

\section{A. Data Source}

Data science techniques assemble valuable information and implement them in a standardized format. The parameters average annual rainfall, meteorological drought category and probabilities of drought were taken up for a thirty-year period (1987 to 2017).

The data was collected from "Indian Meteorological Department" (IMD) of 117 years (1901 to 2017), comprising monthly observations for all 36 meteorological / climatic subdivisions was considered for the following study [4].

The inter- annual and decadal variability of monsoon over India was examined by selecting latest 30-year period (1971- 2001) from a database of 131 years [28]. India receives most of its rainfall in June - September. "Fig. 1".

According to climatology community, drought is categorized into meteorological, hydrological and socioeconomic droughts. The above subdivisions are classified according to the percentage of rainfall deficiency "Fig. 2". If the deficit is $26-50 \%$ of the normal rainfall, a subdivision is classified as moderately dry and if the deficit in rainfall over normal is above $50 \%$ drought is considered severe [7].

The purpose is to know the meteorological drought class/ category of the fore mentioned subdivisions based on acquired data. Besides we make the possible assessment of meteorological drought categories for the subsequent times.

Basing on the hydrological compartment affected and the related impacts we can differentiate between meteorological, hydrological, agricultural and socio-economic droughts. The input variables for drought forecasting depend upon different types of droughts to be forecasted [29].

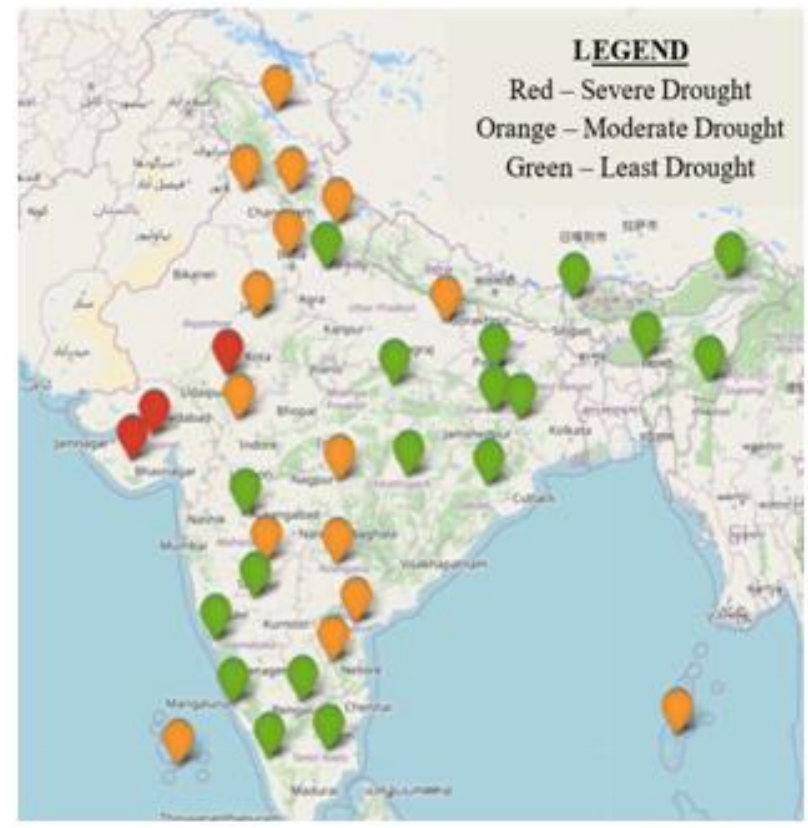

Figure 2: Categories of subdivision

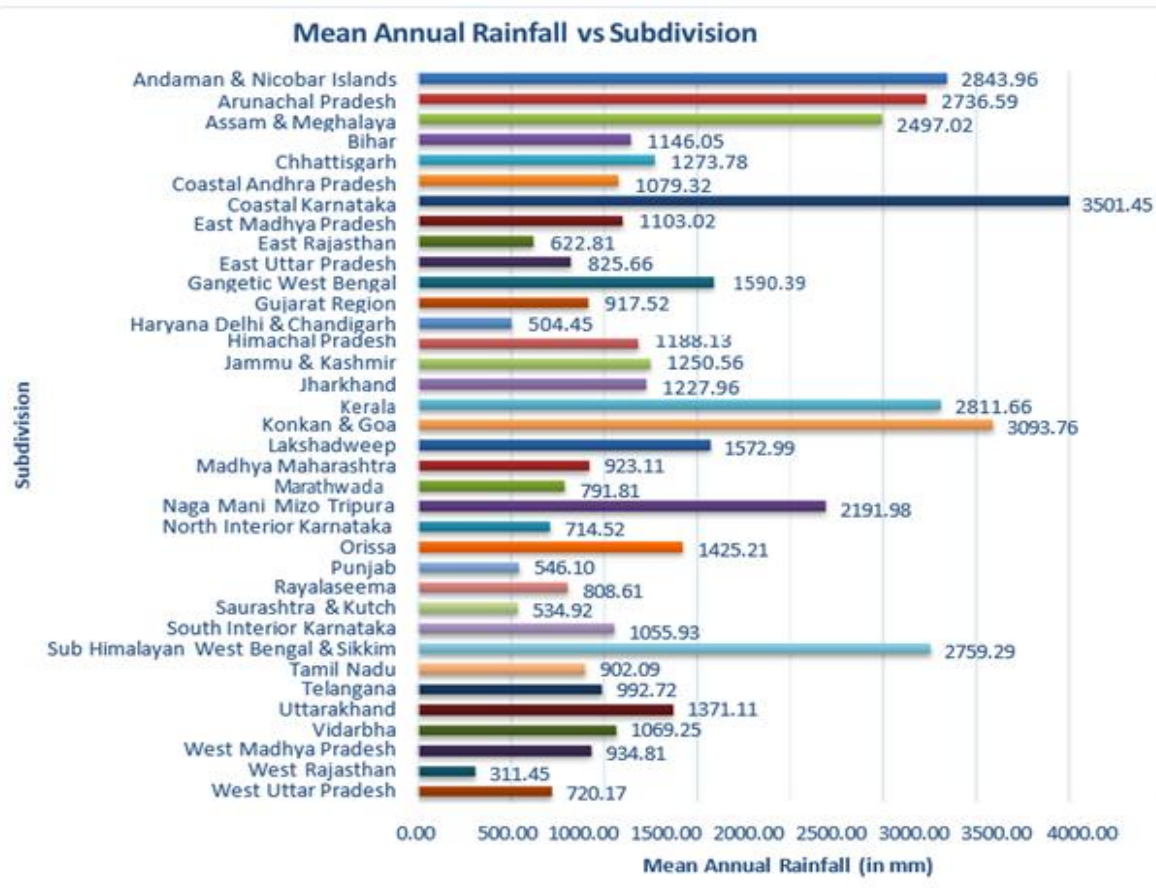

Figure 3: Mean Annual Rainfall of Subdivisions

Volume 9 Issue 2, 2022

www.jissr.net 


\section{B. Data Processing}

The data was organized by taking into consideration of the Mean annual rainfall for every climatic subdivision over the latest 30-year period "Fig .3". The mean annual rainfall attribute over different climatic subdivisions of India were compiled in a structured format and the observations were obtained by employing the drought probability "Table 1".

The term 'climatological normal' is defined as an average magnitude of the meteorological variable over the latest 30 years [5]. Hence, it is important to use the average annual rainfall over the last 30 years (as measured in millimeters). It is mandatory to view the information (basically a scatter plot of features) to interpret the behaviour of data. A scatter plot is taken by computing the mean annual rainfall and probability of subdivisions on the $\mathrm{x}$ and $\mathrm{y}$ axes respectively "Fig.4".

The following study involves the utilization of Machine Learning models such as SVM and DT. The techniques were employed for assessing meteorological drought basing on the data over a period of 30 years (1987-2017).
SVM is a supervised learning method used in classification or regression. It has gained momentum in the areas that has historically been and is being practiced. Now, the data frame was divided into the testing and training sets using "traintest- split" method. The above-mentioned training set was used to train the SVM model. The testing set was used to examine the model and calculate the model score. For better training, the test size was taken as 0.3 (30\% of the data points). The parameters namely, gamma and regularization are taken as 100 and 10 respectively.

Decision tree is indeed an estimation model and is mostly used while clustering data. During the model learning process, the upside-down tree is made from top to bottom or from general to unique format. Decision trees identify the instances in such a tree-like flowchart, where a human spectator can easily grasp the relationship among variables. Data mining includes preparation of data comprising of different phases like data collection, pre-processing and analysis [30].

Table I: Structured form of data

\begin{tabular}{|c|c|c|c|c|}
\hline Subdivision & Average Annual Rainfall & Probabilities & Location & Meteorological Drought Categories \\
\hline Andaman \& Nicobar Islands & 2843.958065 & 13 & {$[11.7401,92.6586]$} & MODERATE_DROUGHT \\
\hline Arunachal Pradesh & 2736.593548 & 5 & {$[28.218,94.7278]$} & LEAST_DROUGHT \\
\hline Assam \& Meghalaya & 2497.019355 & 1 & {$[25.467,91.3662]$} & LEAST_DROUGHT \\
\hline Bihar & 1146.054839 & 8 & {$[25.0961,85.3131]$} & LEAST_DROUGHT \\
\hline Chhattisgarh & 1273.777419 & 8 & {$[21.2787,81.8661]$} & LEAST_DROUGHT \\
\hline Coastal Andhra Pradesh & 1079.316129 & 10 & {$[15.9129,79.74]$} & MODERATE_DROUGHT \\
\hline Coastal Karnataka & 3501.453333 & 5 & {$[12.9141,74.856]$} & LEAST_DROUGHT \\
\hline East Madhya Pradesh & 1103.022581 & 8 & {$[24.5362,81.3037]$} & LEAST_DROUGHT \\
\hline East Rajasthan & 622.812903 & 17 & {$[26.9124,75.7873]$} & MODERATE_DROUGHT \\
\hline East Uttar Pradesh & 825.658065 & 10 & {$[26.7606,83.3732]$} & MODERATE_DROUGHT \\
\hline Gangetic West Bengal & 1590.387097 & 1 & {$[23.3322,86.3616]$} & LEAST_DROUGHT \\
\hline Gujarat Region & 917.522581 & 21 & {$[22.7739,71.6673]$} & SEVERE_DROUGHT \\
\hline Haryana Delhi \& Chandigarh & 504.451613 & 17 & {$[28.9931,77.0151]$} & MODERATE_DROUGHT \\
\hline Himachal Pradesh & 1188.132258 & 16 & {$[31.1048,77.1734]$} & MODERATE_DROUGHT \\
\hline Jammu \& Kashmir & 1250.563333 & 20 & {$[33.7782,76.5762]$} & MODERATE_DROUGHT \\
\hline Jharkhand & 1227.958065 & 4 & {$[23.6102,85.2799]$} & LEAST_DROUGHT \\
\hline Kerala & 2811.658065 & 8 & {$[10.8505,76.2711]$} & LEAST_DROUGHT \\
\hline Konkan \& Goa & 3093.758065 & 7 & {$[15.2993,74.124]$} & LEAST_DROUGHT \\
\hline Lakshadweep & 1572.993548 & 10 & {$[10.57,72.64]$} & MODERATE_DROUGHT \\
\hline Madhya Maharashtra & 923.106452 & 7 & {$[19.8762,75.3433]$} & LEAST_DROUGHT \\
\hline Marathwada & 791.806452 & 14 & {$[18.207,76.1784]$} & MODERATE_DROUGHT \\
\hline Naga Mani Mizo Tripura & 2191.983871 & 9 & {$[24.6637,93.9063]$} & LEAST_DROUGHT \\
\hline North Interior Karnataka & 714.516129 & 8 & {$[16.8302,75.71]$} & LEAST_DROUGHT \\
\hline Orissa & 1425.212903 & 4 & {$[20.9517,85.0985]$} & LEAST_DROUGHT \\
\hline Punjab & 546.103226 & 17 & {$[31.1471,75.3412]$} & MODERATE_DROUGHT \\
\hline Rayalaseema & 808.612903 & 17 & {$[14.4673,78.8242]$} & MODERATE_DROUGHT \\
\hline Saurashtra \& Kutch & 534.922581 & 24 & {$[21.8467,70.812]$} & SEVERE_DROUGHT \\
\hline South Interior Karnataka & 1055.925806 & 7 & {$[12.9716,77.5946]$} & LEAST_DROUGHT \\
\hline pub Himalayan West Bengal \& Sikkim & 2759.293548 & 5 & {$[27.533,88.5122]$} & LEAST_DROUGHT \\
\hline Tamil Nadu & 902.090323 & 9 & {$[11.1271,78.6569]$} & LEAST_DROUGHT \\
\hline Telangana & 992.722581 & 13 & {$[18.1124,79.0193]$} & MODERATE_DROUGHT \\
\hline Uttarakhand & 1371.109677 & 13 & {$[30.0668,79.0193]$} & MODERATE_DROUGHT \\
\hline Vidarbha & 1069.254839 & 12 & {$[21.1286,79.0964]$} & MODERATE_DROUGHT \\
\hline West Madhya Pradesh & 934.806667 & 10 & {$[23.3315,75.0367]$} & MODERATE_DROUGHT \\
\hline West Rajasthan & 311.451613 & 25 & {$[24.8829,74.623]$} & SEVERE_DROUGHT \\
\hline West Uttar Pradesh & 720.167742 & 8 & {$[28.5904,78.5718]$} & LEAST_DROUGHT \\
\hline
\end{tabular}


Data mining strategy is grounded on given dataset analysis demonstrated by parameters. The data set includes previously defined classes recognized by the class attribute mark.

These classes are specified by an attribute. After preparing the data sets, they are studied to fit the classifier.

The data scrutiny and development process are replicated until the most appropriate model is achieved. A basic validation test is a noteworthy way to examine the reliability of the model.

Commonly, about $5-33 \%$ of the data is allocated as testing data while the other part of the percentage is used for the training phase.

In a classification model, the error rate is calculated by dividing the number of classes categorized as accurate by the number of all cases. Generally, the decision-making tree and the rule- based structures explicitly reveal the results of an event. Therefore, the method developed and verified can be explicitly employed as a framework model and could be replicated in other systems.

\section{Results}

In current scenario, with the advancements in information technologies, data mining methods became essential and the observable data helps in addressing environmental concerns. It is vital to acknowledge and analyse the environment which plays an essential role in existence of life on our planet.

In the following work, assessment of meteorological drought categories in Indian climatic zones, based upon precipitation and drought probabilities were taken into account. Based on the changing criteria of annual rainfall and probability, the concept of determining the category was used to classify a subdivision.

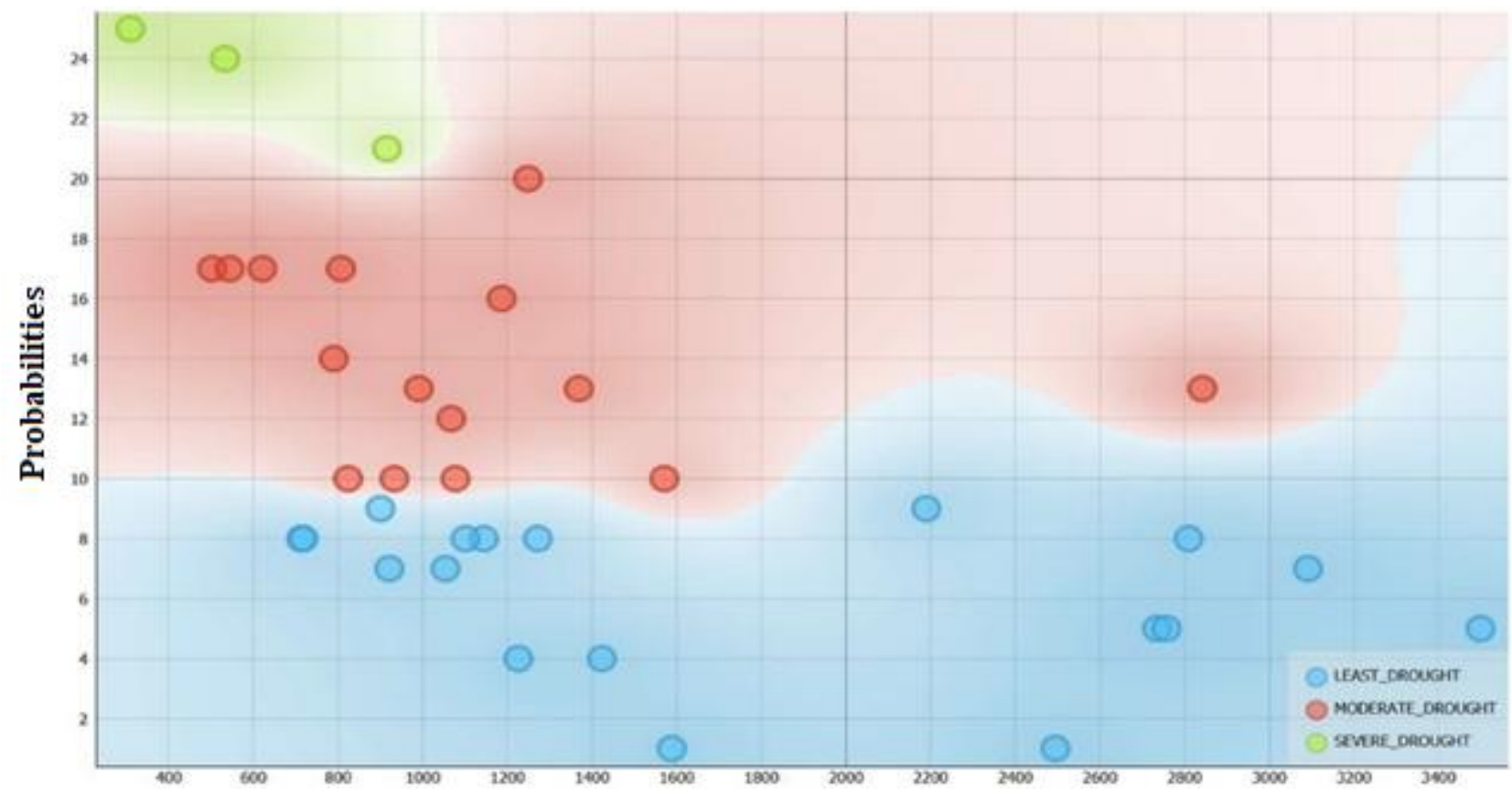

AVG ANNUAL RAINFALL

Figure 4: Scatter plot with Mean annual rainfall Vs Probability

The whole process is summarized by a pipeline diagram"Fig. 5". Employing the two ML algorithms- SVM and DT, it was observed that they worked with an accuracy score of $86.87 \%$ and $100 \%$ respectively. For training purpose, $70 \%$ data points were utilized and the other $30 \%$ was used for testing.

The 'random state' parameter resulted in a balanced choice of the classes in the test set for monitoring the model. For better classification of results, it is mandatory to select a tree that makes decision nodes with minimal entropy. It is noticeable that decision tree performed better in projecting the classification with an accuracy score of $100 \%$ and the f1score of 1.00 indicating excellent precision and recall.

In monitoring, the possible reasons for greater accuracy of Decision Tree when compared with Support Vector Machine is because tree-based methods are non-parametric and not being influenced by the outliers / multicollinearity. Meanwhile, the scatter plot derived is not linearly classifiable without any kernel trick. Based upon the results, the same model can be replicated to further assessing minor district- level drought category assessment by supplying necessary data and other Machine Learning algorithms as the opportunities for future work. 


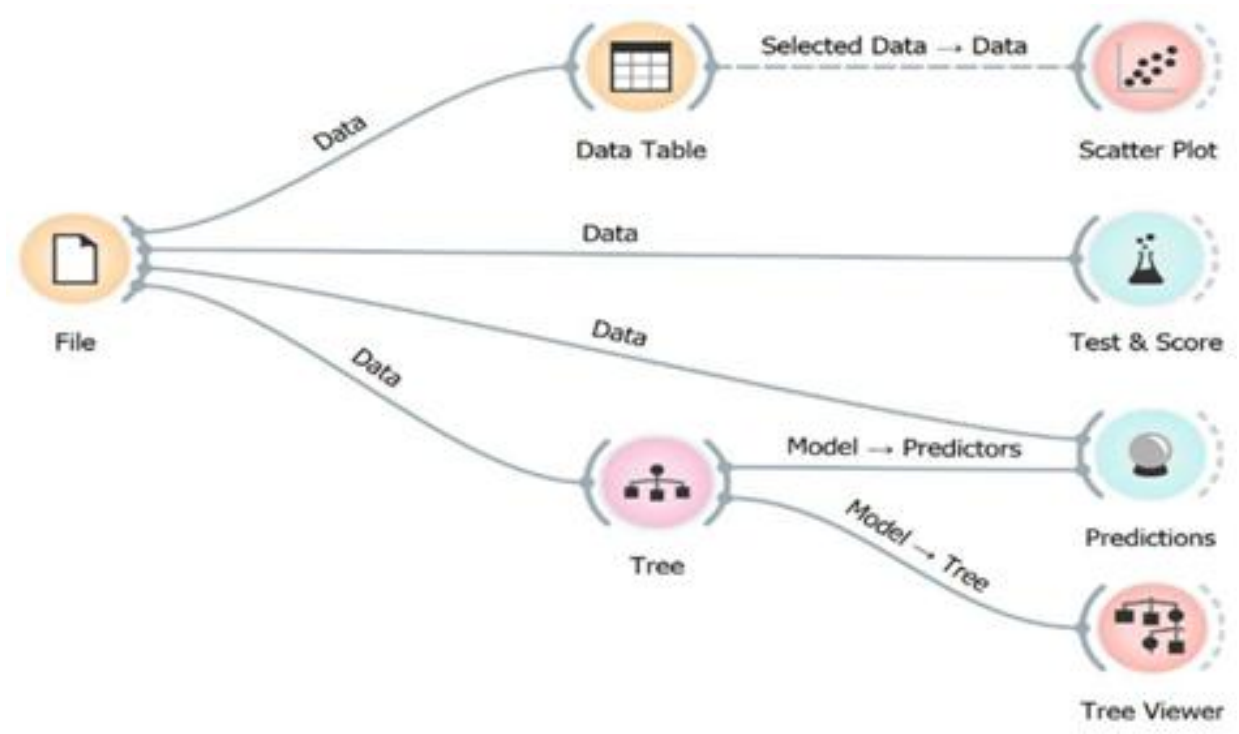

Figure 5: Pipeline diagram of Process

\section{Discussion}

In order to minimize its impacts, the notion of risk assessment is essential in the management and forecasting of droughts. Data mining tools by extraction of formulae and the rules allow assessment/ prediction for the subsequent times by using computational technology. Accurate predictions by Data mining will go a way forward and yield valid results for the future. The most noteworthy aspects of this study involved data selection, processing, employing the data mining procedures and the interpretation. After training the model on data sets, they were studied to suit best fit model expressed by attributes. Although improving accuracy rates is important for some implementations, data interpretation is also essential for developing a validated model. This validated model can be directly employed as an implementation and also be replicated for other similar systems to expose the cause of a case.

The results of the following study have exposed that data mining methods for training, testing will show the better performer among ML algorithms. In present work, $86.87 \%$ for SVM and $100 \%$ for DT was the recorded efficiency. However, this may not imply that SVM in assessment cannot go beyond the recorded performance. Which method out performs the other relies on types of problem or the data that is being analysed. DT performed significantly better than SVM on this specific platform, though this may not be the case in all situations. Previous research indicated better efficiency of SVM in the assessment of drought [13]. Decision tree methods performed better compared to other approaches in another research investigation [26].

\section{Conclusion}

Development in ML, data bases and the Information Technology play a key role in yielding valuable results. Data mining methods are successful in analysing the drought formation conditions and future possibilities of drought. Expecting that the nearby future will not significantly vary from the persisting one, simple predictions that may remain true in future could be made possible by the laws derived from previous results.

The research findings have been reliable with more accuracy. ML algorithms are significant in assessment of meteorological drought. Climatic zones in India having diverse variance in precipitation over time scales, can be better addressed by applying right data mining models. Assessing meteorological drought by SVM and DT techniques can be further calibrated with more accuracy.

These methods along with optimization techniques can be used in a right direction for further research. It is worth mentioning that drought assessment in various Indian regions using precipitation data can further be applied to soil moisture, humidity, wind speed parameters and analysing by data mining. By the following research, we can also address preventive steps to be taken for drought, rather than making corrective actions after drought occurrences.

\section{Acknowledgement}

I would like to extend my thanks to Dr. N. Murali Mohan, researcher in agroforestry for his valuable suggestions and support.

\section{References}

[1] Pereira, L.S., Cordery, I. and Iacovides, I., 2002, Coping with water scarcity, UNESCO IHP VI, Technical Documents in Hydrology, 58, pp.269.

[2] Stahl, K., 2001, Hydrological drought. A study across Europe. Ph.D. thesis. Albert-Ludwigs University Freiburg, Freiburg, Germany.

[3] Nadarajah, S., 2009, A bivariate Pareto model for drought. Stoch. Environ. Res. Risk Assess.23, pp.811822.

[4] Shewale, M.P. and Shravan Kumar, 2005, Climatological Features of Drought Incidences in India, Climatology No. 21, Indian Meteorological Department, Govt. of India. pp. 4-15. 
[5] Roy, A.K. and Hirway, I., 2007, Multiple Impacts of Droughts and Assessment of Drought Policy in Major Drought Prone States in India. Project Report Submitted to the Planning Commission, Government of India, New Delhi. pp.13.

[6] Reddy, S.R., 2008, Principles of crop production. Kalyani Publishers, Ludhiana, pp.256.

[7] Saxena, M.C., 2012, Harnessing the potential of dry areas for ensuring future food security in India. A lecture delivered as $42^{\text {nd }}$ Lal Bahadur Shastri Memorial Lecture at IARI, New Delhi on 16 February, 2012.

[8] Tripathi, S.H., Srinivas V.V. and Nanjundiah R.S., 2006, Downscaling of precipitation for climate change scenarios: A support vector machine approach. J. Hydrol. 330: pp.621-640.

[9] Han, D., Chan, L. and Zhu, N., 2007, Flood forecasting using support vector machines. J. Hydroinformatics. 9(4): pp267-276.

[10] Wang, W., Men. C. and Lu, W., 2008, Online Prediction model based on support vector machine. Neurocomputing 71: pp. $550-558$.

[11] Behzad, M., Asghari, K., Eazi, M. and Palhang. M., 2009, Generalization performance of support vector machines and neural networks runoff modelling. Expert system with Applications, 36(4) ): 7624 -7629.

[12] Velickov, S. and Solomatine, D.P. 2000, Predictive data mining. Practical examples. Artificial Intelligence in Civil Engineering. Proceed. $2^{\text {nd }}$ Joint Workshop. March 2000, Cottbus, Germany, pp.1-17.

[13] Vapnik, V. N and Cortes, C., 1995, Support Vector Networks. Machine Learning, 20: pp. 273-297.

[14] Cover, T.M., 1965, "Geometrical and Statistical Properties of Systems of Linear Inequalities with Applications in Pattern Recognition", IEEE Trans. Elec. Comp., EC- 14: pp. 326-334.

[15] Dibike, Y.B., Velickov, S., Solomatine, D.P. and Abbott, M.B., 2001, Model induction with support sector machines. Introduction and applications. J. Computing in Civil Engineering. 15(3): pp.208-216.

[16] Solomatine, D.P., 2002, Application of data-driven modelling and machine learning in control of water resources. In: Computational intelligence in control. Idea Group Publishing, London, U.K, pp.197-217.

[17] Solomatine, D.P. and Dulal, K.N., 2003, Model trees as an alternative to neural networks in rainfall-runoff modelling. J. Hydrological Sciences. 48 (3), pp. 399411.

[18] Poggio T., Torre, V. and Koch, C., 1985, Computational Vision and regularization theory. Nature, 317: pp. 314-319.

[19] Florian, T.B., Dragan, A.S. and Godfrey, A.W., 2003, Water Reservoir Control with Data Mining. J. Water Res. Plan. Man. 129, pp.26-34.

[20] Sudha, V., Ambujam, N.K. and Venugopal, K., 2006, A data mining approach for deriving irrigation reservoir operating rules. Conference on Water Observation and Information System for Decision Support, 23-26 ${ }^{\text {th }}$ May, Orhid, Macedonia, pp.9.

[21] Quinlan, J.R., 1993, C 4.5 Programs for machine learning. Morgan Kaufmann Publishers, Inc., San Mateo, CA, USA, pp. 299.

[22] Tadesse, T., Wilhite, D.A., Harms S.K., Hayes M.J. and Goddard S., 2004, Drought monitoring using data mining techniques. A case study for Nebraska, USA, Nat. Hazards, 33, pp.137-159.

[23] Bigus, J. P., 1998, Data Mining with Neural Networks: Solving Business Problems from Application Development to Decision Support, McGraw-Hill, New York, pp.220.

[24] Cabena, P.H., Stadler, R., Verhees, J. and Zanasi, A., 1998, Discovering Data Mining: From Concept to Implementation, IBM, New Jersey, pp.195.

[25] Taghi Sattari, M., Anli, A.S., Apaydin. H. and Kodal, S., Decision trees to determine the possible drought periods in Ankara. Atmosfera [online]. 2012, vol.25, n.1, pp. 65-83. ISCN0187-6236.

[26] Bhattacharya, B., Price, R.K. and Solomatine, D.P., 2004, A data mining approach to modelling sediment transport. $6^{\text {th }}$ International Conference on Hydroinformatics. World Scientific Publishing. Singapore, pp. 1-8.

[27] Nhu, V.H., Zandi, D., Shahabi, H., Chapi, K., Shirzadi, A., Al-Ansari, N., Singh, S.K., Dou, J., Nguyen, H. Comparison of Support Vector Machine, Bayesian Logistic Regression, and Alternating Decision Tree Algorithms for Shallow Landslide Susceptibility Mapping along a Mountainous Road in the West of Iran. Appl. Sci. 2020, 10(15):5047.

[28] Kripalini, R. H., Kulkarni, A. and Sabade, S. S. 2003, Indian Monsoon variability in a global warming scenario. Natural Hazards, Kluwer Academic Publishers 29:pp.189-206.

[29] Mishra, A.K., Singh, V.P. and Desai, V.R., 2009, Drought characterization a probabilistic approach. Stoch. Environ. Res. Risk Assess.23, pp.41-55.

[30] Han, J. And Kamber, M., 2006, Data Mining: Concepts and techniques. Morgan Kaufmann Publishers, Elsevier, San Francisco, CA. USA, pp.770. 